\title{
Sentidos sobre Ciência e Tecnologia no Rap nacional
}

João Paulo Ganhor

Irlan von Linsingen

\section{Resumo}

No intuito de contribuir com as investigações sobre as especificidades da Educação Científica e Tecnológica em contextos de periferias urbanas, neste artigo - que é parte de pesquisa em desenvolvimento no âmbito de mestrado acadêmico em Educação Científica e Tecnológica - discutimos a pertinência do Rap nacional na articulação de práticas pedagógicas mais significativas e sensíveis aos diferentes olhares sobre Ciência e Tecnologia (CT) que têm transpassado os espaços escolares. Para isso, estão sendo coletadas e analisadas produções musicais dos grupos mais difundidos nacionalmente, que de alguma forma se refiram à ciência e tecnologia, fundamentando-as na Análise de Discurso da escola francesa preconizada por Michel Pêcheux e nos Estudos Sociais da Ciência e da Tecnologia, ou Estudos CTS. Buscamos compreender como os sentidos emergidos no âmbito do Rap nacional podem contribuir para a explicitação de problemáticas próprias das relações da CT nesses contextos marcados por descaso e injustiça social, oferecendo gestos de deslocamentos interpretativos em relação aos sentidos dominantes. Esses novos olhares podem constituir rico material paradidático para elaboração e articulação de práticas mais referenciadas nas questões e espaços culturais desses contextos, buscando uma educação científica comprometida com processos socioinclusivos e democracia sociotécnica.

Palavras-chave: Educação Científica Urbana, CTS, Hip Hop.

\section{Abstract}

\section{Senses on Science e Technology in the Rap national}

To contribute to the investigations about the specificity of Scientific and Technological Education in peripheries contexts, in this article - which is part of research being developed within academic Master's in Science and Technology Education - discussed the relevance of the national Rap in the articulation of pedagogical practices more significant and sensitive to different perspectives on Science and Technology (CT) that have pierced the school spaces. For this, are being collected and analyzed the musical productions of the most widespread groups nationally, that somehow relate to science and technology, basing them on Discourse Analysis of French school proposed by Michel Pêcheux and Social Studies of Science and Technology or CTS studies. We seek to understand how the senses emerged within the national Rap can contribute to the clarification of own problematic relations of CT in these contexts marked by neglect and social injustice, offering gestures of interpretive shifts in relation to dominant meanings. These new perspectives may provide rich paradidactic material for development and articulation of the more referenced in issues and practices and cultural spaces of this contexts, seeking a scientific education engaged with socioinclusive 
processes and sociotechnical democracy.

Keywords: Urban Science Education, CTS, Hip Hop.

\section{Introdução}

Tem se consolidado no cenário internacional de pesquisas em educação - principalmente nos Estados Unidos da América do Norte - a existência do campo Educação Científica Urbana, que se propõe analisar primordialmente as especificidades educacionais em comunidades urbanas excluídas (ressalta-se que o conceito de exclusão, tem apresentado grande diversidade de enfoques e significados, abarcando uma infinidade de processos superpostos de exclusões cultural, espacial, social e econômica) que convivem com altos índices de segregações e apresentam componentes culturais extremamente específicos, diretamente ligados à cultura negra e latino-americana. Esse campo tem na justiça social seu princípio educacional fundamental (SANTOS, 2008, p. 119) e, assim, assume como finalidade explícita a luta por uma transformação social que rompa com as históricas e sedimentadas injustiças e reconheça os diferentes traços culturais que formam a sociedade de maneira geral.

No Brasil, embora poucos, alguns esforços têm sido realizados nessa direção. Trabalhos como o de Silva, Dysarz e Fonseca (2011), propõem a articulação de práticas ligadas à agroecologia em escolas urbanas como esforço de inclusão sociotécnica, em sintonia com as perspectivas defendidas pelo campo dos Estudos CTS (Ciência-Tecnologia-Sociedade); o de Torres et al (2008) mobiliza diferentes ferramentais teóricos na tentativa de analisar problemas específicos de comunidades carentes de políticas públicas, obtendo temas geradores mais pertinentes que rompam com um conteudismo curricular muito frequente no Ensino de Ciências. Ressalta-se, ainda, a existência na tabela de áreas de conhecimento da CAPES, como tópico específico da educação, a linha Educação em Periferias Urbanas. 
Toda reflexão acerca dos contextos brasileiros nessas perspectivas, deve necessariamente pôr em relevo as particularidades que marcam idiossincraticamente a formação histórica de nosso país. O processo de urbanização brasileiro foi - e tem sido - diferente dos países industrializados centrais. Estes últimos apresentaram um "crescimento através da acumulação tecnológica, enquanto nos países subdesenvolvidos essa acumulação foi principalmente demográfica" (SANTOS, 1980, p. 96). Acrescido a isso, muitos autores têm apontado que o que se denominou de movimento CTS surgiu no contexto desses mesmos países ${ }^{1}$, cujas populações possuíam relativa satisfação das condições materiais e, assim, suas reivindicações eram em grande medida "pósmateriais" - ao contrário do Brasil, onde um percentual significativo da população não têm satisfeitas as condições mínimas adequadas de sobrevivência (AULER e BAZZO, 2001, p. 3). Nesse sentido, Auler e Delizoicov (2006, p. 2) também ressaltam que na América Latina grande parte da população sofre por carência material, e grande parte dos países vivenciaram experiências coloniais. Mais ainda, no Brasil a transição para o estado democrático tem ocorrido de forma "lenta e incompleta, guardando traços de um passado, ultrapassado apenas diante das leis, mas atualizado com frequência na vida cotidiana" (MAIOLINO, 2008, p. 273).

Diversos autores vêm indicando que na América Latina, "[...] o fim do colonialismo político não significou o fim do colonialismo como relação social" (SANTOS, 2005) e que este processo mantém a "[...] constituição colonial dos saberes, das linguagens, da memória e do imaginário" (LANDER, 2005, p. 26), fortemente fundamentada em um marco europeu-ocidental. Assim, a construção epistemológica europeia é necessariamente excludente, pois propõe a noção de

1 Esse movimento é comumente caracterizado como sendo constituído por duas tradições principais, a saber: europeia e norte-americana (BAZZO, LINSINGEN, PEREIRA, 2003; AULER e BAZZO, 2001). Não obstante, recentemente tem sido explicitada a existência de reflexões e ações acerca das relações da CT também em países da América Latina, iniciados por volta dos anos 1960 e 1970. Guardando suas particularidades, tal perspectiva vem sendo denominada "CTS latinoamericano". Nesse contexto, von Linsingen (2007) afirma que: "Se o movimento CTS se origina na Europa a partir da confluência da sociologia da ciência desenvolvida por Robert Merton com um enfoque institucional e da relação entre ciência e poder destacada por Bernal nos anos 1930, bem como dos desenvolvimentos de Solla Price defendendo um enfoque interdisciplinar que postulava uma "ciência da ciência", na América Latina a origem do movimento se encontra na reflexão da ciência e da tecnologia como uma competência das políticas públicas. Mesmo não sendo parte de uma comunidade explicitamente identificada como CTS, isso se configurou como um pensamento latinoamericano em política científica e tecnológica (Vaccarezza, 1998), posteriormente identificado como "Pensamento Latino Americano de Ciência, Tecnologia e Sociedade" (PLACTS)" 
universalidade a partir de sua particularidade histórica. Perpetua-se, então, uma "monocultura do saber" (SANTOS, 2005, 2007), onde os saberes não hegemônicos são historicamente ignorados por uma produção de "ausências". Assim, "o que não existe é produzido ativamente como nãoexistente [...] invisível à realidade do mundo" (SANTOS, 2007). Dessa forma, para romper tal estruturação é preciso "indagar outros saberes, outras práticas, outros sujeitos, outros imaginários capazes de conservar viva a chama de alternativas a esta ordem social de hegemonia do capital" (LANDER, 2001, p. 65).

Essas reflexões suscitam importantes perspectivas à Educação Científica, indicando uma necessária ampliação em suas práticas "[...] visando à uma transformação social que aproxime saberes, que considere alternativas à estrutura hegemônica de formação" (VON LINSINGEN e CASSIANI, 2011). Uma educação sensivel aos diferentes olhares sobre CT (RAMOS et al, 2005) e que "vislumbre a polissemia característica da leitura e a pluralidade de formas textuais" (RAMOS, 2010 , p. 18). Dessa maneira, o presente trabalho objetiva contribuir com a permanente articulação de práticas pedagógicas referenciadas e significativas às parcelas da população brasileira residentes nas periferias urbanas, alinhando-se com o apontado por von Linsingen e Cassiani (2011, p. 171), que indicam que a abordagem de conhecimentos de CT apresenta diferenças relevantes quando esta ocorre no local em que esses conhecimentos foram elaborados ou quando desenvolvida em contextos socioculturais distintos.

Diante disso, a proposta central deste trabalho constitui-se em analisar como os discursos do Rap nacional podem desencadear construções/filiações de sentidos relacionados à CT e, principalmente, acerca de como estas se configuram socialmente. Busca-se então responder aos seguintes questionamentos: como se produzem sentidos sobre CT nos discursos do Rap nacional? Eles podem favorecer deslocamentos de sentidos que contribuam para uma educação científica e tecnológica transformadora em termos sociotécnicos?

O Rap - Rhythm and Poetry - surgiu na Jamaica na década de 1960 e foi, posteriormente, integrado ao Movimento Hip Hop. Este último surgiu nos guetos de Nova lorque no início da década de 1970, "unindo práticas culturais dos jovens negros e latino-americanos nos guetos e ruas dos grandes centros urbanos" (MAGRO, 2002, p. 68). No Brasil, esse movimento começou a se estruturar no decorrer da década de 1980, principalmente na cidade de São Paulo, consolidando-se a partir dos anos 1990 e expandindo-se a todo território nacional, fato que ilustra a magnitude que aqui adquiriu. Segundo Andrade (1999) o Rap político tornou-se predominante no cenário brasileiro e caracteriza-se, primordialmente, pela presença marcante de críticas e reivindicações sociais e políticas (além do Rap político, esquematicamente, o Rap brasileiro pode ser dividido em outros estilos, como, por exemplo: i. Rap romântico; ii. Rap gospel; iii. Rap gangsta; iv. Rap de pista)

Ressalta-se, dessa maneira, a grande relevância que esse movimento possui nos contextos das periferias urbanas e, principalmente, na mobilização identitária de grande parcela de sua 
juventude (ANDRADE, 1999) - que não deixa de valorizar também inúmeras outras manifestações culturais e artísticas. Consequentemente, guarda um grande potencial pedagógico tanto no contexto de educação informal como em práticas da educação formal (MAGRO, 2002). Não obstante, observa-se que as escolas têm marginalizado tais expressões culturais que transpassam seu ambiente e, assim, têm permanecido impermeáveis às experiências juvenis que ocorrem fora de seu âmbito oficial (SILVA, 1999, p. 25). Segundo Freire (1992, p. 85), “[...] subestimar a sabedoria que resulta necessariamente da experiência sociocultural é, ao mesmo tempo, um erro científico e a expressão inequívoca da presença de uma ideologia elitista". Para esse autor, uma prática pedagógica progressista "[...] não pode desconhecer [...] a leitura de mundo que vêm fazendo os grupos populares, expressa no seu discurso, na sua sintaxe, na sua semântica, nos seus sonhos e desejos" (idem, p. 20).

Nessa perspectiva, apontamos aqui a pertinência para a Educação em Ciências da análise de um movimento artístico-cultural de grande importância para a juventude periférica, que influi diretamente em suas construções/filiações de sentidos. Portanto, acreditamos ser oportuno e pertinente a análise de como esses sentidos estão sendo construídos, quais as representações de CT - e suas relações sociais - subentendidas, que ademais podem constituir uma rica fonte de materiais paradidáticos para contribuir nas práticas pedagógicas aderentes a uma perspectiva CTS crítica. Destacamos ainda a importância da reflexão acerca das especificidades da educação científica nesses contextos, sua indispensável postura transformadora e a potencialidade do Rap nessa direção, dada sua forte dimensão de consciência social e política (WELLER, 2000).

Nesse sentido, esta pesquisa pretende contribuir ao elucidar problemáticas específicas da CT com as populações das periferias urbanas e as visões de mundo que estas tenham ou estejam tendo acerca das primeiras, problematizando os temas sociais que têm sido comumente sugeridos no campo CTS, pois o Rap constitui-se de longas descrições do dia-a-dia de jovens dessas regiões (SILVA, 1999 citado por MAGRO, 2002, p. 71). Indo, assim, em direção à uma problemática ressaltada por diversos autores, como Auler (2007), que aponta que os temas, nesse âmbito, têm sido majoritariamente universais, não referenciados nas especificidades dos contextos e definidos sem a participação da comunidade escolar. Corroborando com tal diagnóstico, Carletto, Linsingen e Delizoicov (2006) indicam que os temas propostos por alguns pesquisadores do campo da educação CTS têm surgido primordialmente das percepções dos especialistas. Cenário que pode ser agravado, dada a ampla centralidade que os temas sociais têm adquirido em currículos CTS (SANTOS, 1992, 2002). Pode também contribuir para a explicitação de outros sentidos sobre CT que têm transpassado os ambientes e práticas escolares (somando com os esforços nessa direção iniciados pelo grupo Discursos da Ciência e da Tecnologia na Educação - DICITE - ligado ao Programa de Pós-Graduação em Educação Científica e Tecnológica da Universidade Federal de Santa Catarina - UFSC), problematizando os sentidos dominantes e colaborando na articulação de práticas pedagógicas mais referenciadas e significativas, que 
promovam deslocamentos para interpretações das relações CTS orientadas aos processos socioinclusivos.

\section{Material e Método}

Para realização da análise aqui proposta, utilizaremos músicas dos grupos mais emblemáticos do Movimento Hip Hop no cenário nacional. Dessa forma, a metodologia de trabalho é dividida em quatro momentos principais: i) Identificação dos grupos; ii) Coleta de toda discografia dos grupos selecionados; iii) Identificação de músicas com temáticas relacionadas à CT; iv) Análise de acervo final.

Dada à extensão, complexidade e especificidades do Movimento Hip Hop no contexto brasileiro a análise do movimento é realizada com base na seleção de um determinado número de artistas. Foi usado como critério de escolha o nível de difusão dos grupos no território brasileiro, como garantia de opção mais representativa a um maior número de contextos. Para isso, foi utilizada a Revista Rap Nacional, veículo de destaque e maior circulação dentro do gênero no Brasil. Ela conta atualmente com 9 (nove) edições já publicadas. Assim, foram catalogados todos os grupos citados nas capas das revistas, tanto os das matérias principais como os de reportagens secundárias que também figuraram nas capas. Dessa lista inicial, apenas os que apresentaram maior recorrência de aparições no conjunto das edições analisadas foram, por fim, selecionados. Após essa primeira identificação, foram elaboradas fichas informativas individuais, como mostradas adiante (tabela 2), para cada grupo pertencente à lista final, contendo uma breve relação de informações pertinentes a cada um. Em seguida, foram coletadas todas as discografias dos grupos selecionados e estão atualmente sendo realizadas as transcrições de cada música individualmente. Essa etapa é realizada principalmente através de sites relacionados, consulta ao acervo do Projeto "É nóis na fita" - coordenado pela Profa. Dra. Anna da Silva (IEL/UNICAMP) - e transcrições diretas, quando necessárias.

Em seguida, serão selecionadas todas as músicas que possuam temáticas relacionadas à CT. Para isso será realizada a leitura e audição completa de todas as músicas, buscando pontos que remetam diretamente à ciência e/ou à tecnologia, seus produtos/artefatos, suas práticas, seus atores, suas consequências e relações com a sociedade, etc. Essa seleção dará origem a um acervo principal (aqui denominado Acervo macro), constituído por todas as músicas que contemplem em alguma medida assuntos relacionados à CT. Como parte complementar do trabalho pretendemos realizar a divulgação desse primeiro acervo principal, através de blogs ou outras plataformas digitais, objetivando fornecer um conjunto de materiais potencialmente pertinentes para a elaboração de práticas pedagógicas mais referenciadas, dialogantes com as culturas juvenis. Por fim, será realizado um segundo recorte, selecionando-se apenas as músicas que tratem diretamente das complexas relações CTS. 
As músicas que constituirão esse último acervo serão analisadas fundamentando-se na Análise de Discurso (AD) da escola francesa preconizada por Michel Pêcheux, segundo a qual todo discurso configura-se como objeto simbólico e espaço de construção/filiação e circulação de sentidos (VON LINSINGEN e CASSIANI, 2011; CASSIANI, VON LINSINGEN, GIRALDI, 2008). Assim, a linguagem não é entendida como mera ferramenta de comunicação, mas como local de constituição e integração dos sujeitos a determinados contextos histórico-sociais (FLÔR e CASSIANI, 2011; VON LINSINGEN e CASSIANI, 2011; CASSIANI, VON LINSINGEN, GIRALDI, 2008). Destaca-se, dessa maneira, o caráter material e histórico da linguagem, sustentando que ela está presente em toda forma de conhecer. Consequentemente, os sentidos não estão dados a priori, mas referenciam-se em formulações historicamente sedimentadas (CASSIANI, VON LINSINGEN, GIRALDI, 2008). Surge, então, a necessidade de considerar os educandos-educadores como produtores de sentidos, como sujeitos que interagem com diversas culturas, além da científica e tecnológica (ALMEIDA, SILVA, MACHADO, 2001).

Dentre essas culturas, figura o Movimento Hip Hop (ou o movimento negro de maneira geral) que é tomado como parte de uma discursividade do mundo urbano, como flagrantes que constantemente emergem e fornecem indícios simbólicos das práticas sociais ali desencadeadas, como falas desorganizadas que desestabilizam e deslocam os sentidos da/na cidade (ORLANDI, 2004). Ou, nas palavras de Orlandi (idem, p. 31):

"O rap, a poesia urbana, a música, os grafitos, pichações, inscrições, outdoors, painéis, rodas de conversa, vendedores de coisa-alguma, são formas do discurso urbano. É a cidade produzindo sentidos [...] O rapper não fala sobre a cidade de um lugar externo a ela. Como arte, o rap é uma "instalação" no domínio da música: ela ao mesmo tempo se estampa e é parte do urbano [...] A música rap (ritmo e poesia: rep) é uma dessas modalidades entre as diferentes textualizações do discurso urbano"

\section{Análise e discussão}

Em concordância com os critérios apresentados no item anterior, foram selecionados os grupos mais recorrentemente citados na Revista Rap Nacional. Essa seleção originou uma lista final constituída por dez artistas que, em alguma medida, contemplam um amplo espectro do Movimento Hip Hop no Brasil. Na tabela 1 são listados tais grupos e o número de vezes em que figuraram em qualquer uma das nove capas analisadas: 
Tabela 1 - Grupos mais citados nas capas da revista Rap nacional

\begin{tabular}{|c|c|c||c|}
\hline Grupo & Recorrência & Grupo & Recorrência \\
\hline \hline Racionais MC's & 4 & Pregador Luo & 2 \\
\hline \hline Detentos do Rap & 3 & Criolo & 2 \\
\hline \hline Dexter & 3 & GOG & 2 \\
\hline Facção Central & 2 & Sabotage & 2 \\
\hline \hline Realidade Cruel & 2 & MV Bill & 2 \\
\hline
\end{tabular}

A partir dessa lista foram elaboradas as fichas informativas para cada um dos artistas listados. Elas são formadas por breves informações - como o nome do grupo, região de origem e ano de fundação, além de discografia completa - que além da contribuição esquemática no desenvolvimento do trabalho serão pertinentes na análise, na elucidação das condições de produção que envolve a elaboração dos inúmeros discursos que serão posteriormente analisados.

A tabela 2 ilustra a composição básica das fichas. Nela são mostradas - a título de exemplo - as informações referentes ao grupo Racionais MC's, provavelmente o grupo de maior importância na constituição do movimento no contexto brasileiro e, naturalmente, o mais citado nas edições analisadas, com quatro aparições.

Tabela 2 - Ficha informativa do grupo Racionais MC's

\begin{tabular}{|c|c|}
\hline Nome do grupo & Racionais MC's \\
\hline Cidade & São Paulo \\
\hline Bairro/Região & Capão Redondo/Zona Sul \\
\hline \multirow{2}{*}{ Ano de fundação } & 1988 \\
\hline \multirow{4}{*}{ Discografia } & Holocausto Urbano (1990) \\
\cline { 2 - 3 } & Escolha seu caminho (1992) \\
\cline { 2 - 3 } & Raio X Brasil (1993) \\
\cline { 2 - 3 } & Sobrevivendo no Inferno (1997) \\
\cline { 2 - 3 } & Nada como um dia após o outro dia (2002) \\
\hline
\end{tabular}


A partir das fichas individuais (exemplificada na tabela 2), estão sendo coletadas todas as discografias relacionadas a cada artista e está sendo realizada transcrição de todas as músicas que as compõem. Dada à sua extensão, esse acervo não será aqui exposto. Entretanto, para ilustrar parte do que constituirá o acervo a ser posteriormente publicado e do corpus de análise, e seguindo a exemplificação com o artista referente à ficha da tabela 2, é apresentada a seguir uma música desse mesmo grupo, que faz parte do acervo selecionado e trata diretamente de assuntos que envolvem temáticas ligadas à ciência e tecnologia. Trata-se de um trecho da música "Vivão $e$ Vivendo", do último álbum lançado intitulado Nada como um dia após outro dia (RACIONAIS MC'S, 2002):

"Eu tenho fé, amor e afeto / No século 21 / Onde as conquistas científicas / Espaciais, medicinais / E a confraternização dos homens / E a humildade de um rei / Serão as armas da vitória para a paz universal"

O trecho que compõe a música citada é uma referência - e homenagem - retirada da música "A benção mamãe, $A$ benção papai", de Jorge Ben Jor, que compõe o álbum "Sonsual" lançado no ano de 1984. Tal tipo de referência a outros artistas ou grupos é frequente dentro do Rap, e materializa-se primordialmente através de samples, que são extratos retirados de outras músicas e podem ser desde pequenos loops de melodias, ou bases da música, sons de determinado(s) instrumento(s), falas ou cantos, etc, constituindo um processo, através do qual o Movimento Hip Hop articula e se apropria de diversos referenciais e elementos culturais de outros períodos e localidades (somente possível a partir de artefatos científico-tecnológicos desenvolvidos no século XX, como rádio e transmissão, discos, etc.). Através deles manifesta-se uma de suas principais fundamentações e ligações ao Movimento Negro de maneira geral, seja a grandes nomes da música negra - como o próprio Jorge Ben - ou a ícones históricos desse movimento - Malcolm X, Martin Luther King, Marcus Garvey - que são recorrentemente citados estética e musicalmente no contexto do Movimento Hip Hop.

Essa pequena passagem retrata em alguma medida uma postura esperançosa em relação ao desenvolvimento científico e tecnológico, que é visto como capaz, dentro de uma certa conjuntura social e política, de colaborar no estabelecimento de um estado de paz universal. Nesse contexto, as conquistas científicas, espaciais e medicinais são significadas como entidades que guardam em si possibilidades de contributo à emancipação e justiça social.

Essa concepção é oposta ao esperado e, provavelmente, majoritário nos discursos do Rap nacional em relação à $\mathrm{CT}$, que seria uma postura mais pessimista e fatalista, que trataria o desenvolvimento científico dentro de uma perspectiva de recorte classista. Sendo este necessariamente atrelado à ampliação das regalias sociais das classes economicamente dominantes (ou simplesmente os "playboys") e, consequentemente, das condições que os obrigam e limitam às atuais situações de descaso e exclusão social. 
Em suma, tomando a CT como instrumento de dominação, não de emancipação social (como sugere o trecho indicado), se aproximando da tese de Marcuse - defendida também por Habermas e outros autores - para a qual a ciência e a técnica legitimam a dominação, pois, ao amplificar gradativamente a eficácia da dominação da natureza pelo ser humano, as metodologias científicas acabam proporcionando as bases necessárias a uma consequente ampliação também da dominação do humano sobre o próprio humano. (SANTOS \& MORTIMER, 2002, p. 1)

Tal exemplo ilustra como os discursos do Rap podem ser apreendidos na Educação Científica, no intuito de desencadear reflexões acerca das possibilidades de contribuição do atual conhecimento sobre $\mathrm{CT}$, favorecendo problematizações que, além de uma mera crítica vazia, proponham a reflexão das possibilidades de ressignificação desse conhecimento.

Dada à magnitude que o empreendimento $\mathrm{CT}$ tem adquirido nos últimos séculos e a influência cada vez mais marcante na vida humana, e os discursos que ressaltam os seus benefícios, cabem as perguntas: a história tem testemunhado mais exemplos da $\mathrm{CT}$ a serviço de um projeto emancipador ou, ao contrário, tem amplificado as relações de poder e dominação historicamente constituídas e que constante e dinamicamente se reconfiguram? Qual a proximidade das práticas científico-tecnológicas aos valores humanos como os mencionados na música: confraternização, humildade, paz?

\section{Considerações finais}

Neste trabalho foi assumido que o Rap pode ser apreciado como elemento de cultura popular e, assim, tomado "como prática local e temporalmente determinada, como atividade dispersa no interior da cultura dominante, como mescla de conformismo e resistência" (CHAUÍ, 1993, p. 43) e, assim, configura-se como "revanche da cultura popular" (SANTOS, 2010, p. 144), ao apoderar-se dos meios hegemônicos para elaborar suas críticas e denúncias sociais, próprias das tensões vivenciadas pelas populações periféricas.

Dessa maneira, possui um potencial transformador característico, dada sua forte dimensão de consciência social e política (WELLER, 2000), que pode e deve ser valorizada nos ambientes escolares, principalmente em relação ao recorte educacional aqui proposto: o de pensar especificamente a educação em CT em periferias urbanas. Assim, buscamos indicar que para esses contextos se faz necessária uma fundamentação política e pedagógica crítica, diretamente comprometida com os processos de transformação social, ou seja, comprometida com a ressignificação das condições que sustentam nossas formas de organização social e dificultam, ou impedem, a uma parcela extremamente significativa de pessoas de desenvolverem adequadamente suas existências, e a conscientização de sua necessária superação.

Como buscamos evidenciar, especificamente no âmbito da educação científica, seus discursos podem propiciar deslocamentos de sentidos acerca da CT e desencadear reflexões mais 
críticas e localmente contextualizadas quanto às relações CTS. Nesse sentido, sustenta-se que o Rap pode contribuir, ao:

i) Explicitar as problemáticas específicas da CT com as populações das periferias urbanas brasileiras e parte de suas visões de mundo, apontando temas sociais pertinentes, pois são descrições do dia-a-dia de jovens dessas regiões (SILVA, 1999 apud MAGRO, 2002, p. 71);

ii) Fortalecer a finalidade crítica e democrática apregoadas pelos estudos CTS ao dialogar com uma cultura própria dos substratos segregados de nossa sociedade que, segundo Magro (2002, p. 68), apresenta-se como local de conscientização política e exercício da cidadania.

iii) Contribuir na explicitação de outros sentidos sobre ciência e tecnologia (CT) que têm transpassado os ambientes e práticas escolares (somando com os esforços iniciados pelo grupo Discursos da Ciência e da Tecnologia na Educação - DICITE/UFSC), problematizando os sentidos dominantes e contribuindo na articulação de práticas pedagógicas mais referenciadas e significativas.

\section{Referências}

ALMEIDA, M. J. P. M.; SILVA, H. C.; MACHADO, J. L. M. Condições de produção no funcionamento da leitura em educação em física. Revista Brasileira de Pesquisa em Educação em Ciências. Vol. 1, n. 1, p. 5-17, 2001

ANDRADE, E. N. (Org.) Rap e educação Rap é educação. São Paulo: Selo Negro, 1999.

AULER, D. Enfoque Ciência-Tecnologia-Sociedade: pressupostos para o contexto brasileiro. Ciência e Ensino. Vol. 1, n. especial, 2007.

AULER, D.; BAZZO, W. Reflexões para a implementação do movimento CTS no contexto educacional brasileiro. Ciência e Educação. Vol. 1, n. especial. 2001.

AULER, D. DELIZOICOV, D. Educação CTS: Articulação entre pressupostos do educador brasileiro Paulo Freire e referenciais ligados ao movimento CTS. In: Las relaciones CTS em la Educación Científica, 2006, Málaga-Espanha. Anais do V Encontro Iberoamericano sobre Las Rellaciones CTS em la Educación Científica. Málaga: Editora da Universidade de Málaga, 2006, p. 01-09.

BAZZO, W. A.; VON LINSINGEN, I.; PEREIRA, L. T. do V. Introdução aos Estudos CTS. Madrid: Organização dos Estados Iberoamericanos, 2003.

CARLETTO, M. R.; VON LINSINGEN, I.; DELIZOICOV, D. Contribuições a uma educação para a sustentabilidade. In: I Congreso Iberoamericano de Ciencia, Tecnologia, Sociedad y Innovación CTS+I, 2006, México D.F. Memórias do I Congreso Ibero CTS+I, Vol. 1, p. 1-15, 2006. 
CASSIANI, S; VON LINSINGEN, I.; GIRALDI, P. M. Análise do Discurso: enfocando os estudos sobre a Ciência e a Tecnologia na Educação. In: VII ESOCITE - Jornadas Latino-Americanas de Estudos Sociais das Ciências e das Tecnologias. Rio de Janeiro. Vol. 1, p 1-17, 2008.

CHAUÍ, M. Conformismo e Resistência. Aspectos da cultura popular no Brasil. São Paulo: Editora Brasiliense. 5a ed. 1993.

FLÔR, C. C.; CASSIANI, S. O que dizem os estudos da linguagem na educação científica? Revista Brasileira de Pesquisa em Educação em Ciências. Vol. 11, n. 2, 2011.

FREIRE, P. Pedagogia da esperança: um reencontro com a pedagogia do oprimido. Rio de Janeiro: Paz e Terra. 1992.

LANDER, E. A colonialidade do saber: eurocentrismo e ciências sociais. Buenos Aires: Consejo Latinoamericano de Ciencias Sociales - CLASCO, 2005.

- Conhecimento para quê? Conhecimento para quem? Reflexões acerca da geopolítica dos saberes hegemônicos. In: GENTILI, P. (Org.) Universidades na penumbra: neoliberalismo e reestruturação universitária. São Paulo: Cortez, 2001, p. 45-71.

MAGRO, V. M. de M. Adolescentes como autores de si próprios: cotidiano, educação e o HIP HOP. Caderno Cedes Campinas, Vol. 22, no 57, p. 63-75, 2002.

MAIOLINO, A. L. G. Espaço urbano: conflitos e subjetividade. Rio de Janeiro: Mauad X: FAPERJ, 2008.

ORLANDI, E. P. Cidade dos Sentidos. Campinas: Pontes, 2004.

RACIONAIS MC'S. Nada como um dia após o outro dia. São Paulo: Cosa Nostra, 2002.

RAMOS, M. B. Na pauta das aulas de ciências: discussões de controvérsias científicas na televisão. Campinas. Tese de Doutorado: UNICAMP/IG, 2010.

; NASCIMENTO, T. G.; GIRALDI, P. M.; PEREIRA, P. B.; FLOR, C. C.; ZIMMERMAN, N.; FERREIRA, E. P.; CASSIANI, S.; VON LINSINGE, I. Discursos da Ciência e da Tecnologia na Educação. In: Atas do V Encontro Nacional de Pesquisa em Educação em Ciências. Bauru, 2005.

SANTOS, B. S. Renovar a teoria crítica e reinventar a emancipação social. São Paulo: Boitempo, 2007.

Semear outras soluções: os caminhos da biodiversidade e dos conhecimentos rivais. Rio de Janeiro: Civilização Brasileira, 2005.

SANTOS, M. Por uma outra globalização: do pensamento único à consciência universal. Rio de Janeiro: Record, 2010.

A urbanização desigual: a especificidade do fenômeno urbano em países subdesenvolvidos. Petrópolis: Vozes. 1980.

206 DOI: Em andamento.

R. Bras. de Ensino de C\&T 
SANTOS, W. L. P. Educação Científica Humanística em uma perspectiva freireana: resgatando a função do ensino CTS. Alexandria. Vol. 1, no 1. p. 109-131, 2008.

Aspectos sócio-científicos em aulas de química. Belo Horizonte. Tese de doutorado. UFMG/Fae, 2002.

O ensino de química para formar o cidadão: principais características e condições para a sua implantação na escola secundária brasileira. Campinas. Dissertação de mestrado: UNICAMP/FE, 1992.

SANTOS, W. L. P; MORTIMER, E. F. Uma análise de pressupostos teóricos da abordagem C-T-S (Ciência-Tecnologia-Sociedade) no contexto da educação brasileira. Ensaio - Pesquisa em Educação em Ciências. Vol. 2, n. 2, 2002.

SILVA, J. C. G. Arte e Educação: a experiência do movimento Hip Hop paulistano. In: ANDRADE, E. N. (Org.). Rap e educação Rap é educação. São Paulo: Selo Negro, 1999.

SILVA, E.; DYSARZ, F.; FONSECA, A. B. Agroecologia em escolas urbanas alicerçando a perspectiva CTS no ensino de ciências. In: VIII ENPEC, 2011, Campinas. VIII ENPEC, 2011

TORRES, J. R.; GEHLEN, S. T.; MUENCHEN, C.; GONÇALVES, F. P.; LINDEMANN, R. H.; GONÇALVES, F. J. F. Ressignificação curricular: contribuições da investigação temática e da Análise Textual Discursiva. Revista Brasileira de Pesquisa em Educação em Ciências. Vol. 8, n. 2, 2008.

VON LINSINGEN, I. Perspectiva educacional CTS: aspectos de um campo em consolidação na América Latina. Ciência \& Ensino. Vol. 1, n. especial, 2007

VON LINSINGEN, I.; CASSIANI, S. Educação CTS em perspectiva discursiva: contribuições dos estudos sociais da ciência e da tecnologia. Redes (Bernal). Vol. 16, p. 163-182, 2011.

WELLER, W. A construção de identidades através do Hip Hop: uma análise comparativa entre rappers negros em São Paulo e rappers turco-alemães em Berlim. Caderno CRH, Salvador, n. 32, p. 213-232, 2000.

João Paulo Ganhor - Mestrando do Programa de Pós-Graduação em Educação Científica e Tecnológica (PPGECT/UFSC) - Universidade Federal de Santa Catarina (UFSC) joao.ganhor@hotmail.com

Irlan von Linsingen - Doutor em Educação em Ciências pelo Programa de Pós-Graduação em Educação (PPGE/UFSC). Professor do Programa de Pós-Graduação em Educação Científica e Tecnológica (PPGECT/UFSC). Departamento de Engenharia Mecânica - Centro Tecnológico Universidade Federal de Santa Catarina - irlan.von@gmail.com 